\title{
Ontología de la resistencia
}

\section{Ontologie of resistance}

Mario Teodoro Ramírez Universidad Michoacana de San Nicolás de Hidalgo

Resumen

A partir del uso político-social del término "resistencia", este ensayo propone un análisis filosófico del concepto de resistencia a través de ciertos pensadores importantes del siglo XX y lo que va de este siglo. Se analiza así el concepto fenomenológico y ontológico de resistencia en cuanto cualidad ontológica (el Ser es lo que resiste a las determinaciones epistémicas y antropológicas) en Merleau-Ponty y autores recientes vinculados al llamado nuevo realismo o realismo especulativo (Meillassoux, Harman, Ferraris). A través de una recuperación de ideas de Deleuze y Foucault, se ofrece un concepto político de resistencia como proceso "primario" respecto al poder, a partir de lo cual se propone una redefinición de la democracia como el poder de resistencia del pueblo.

Palabras clave: ontología, resistencia, realismo, poder. 


\section{Abstract}

From the political and social use of the term "resistance", this paper proposes a philosophical analysis of the concept of resistance through certain important thinkers of the twentieth century and so far this century. The phenomenological and ontological concept of resistance as ontological quality is analyzed (the Being is what resists epistemic and anthropological determinations) in Merleau-Ponty and recent authors linked to the so-called new realism or speculative realism (Meillassoux, Harman, Ferraris). Through recovery of ideas of Deleuze and Foucault it's offered a concept of resistance as "primary" process with respect to power, from which a redefinition of democracy as the power of the people for resistance.

Keywords: Ontologie, Resistance, Realism, Power.

A Rubi de María

Por la motivación

n los últimos tiempos se ha vuelto usual el término "resisten-
cia" para caracterizar la lucha de diversos movimientos sociales frente a acciones represivas o decisiones inaceptables del poder político o económico. ${ }^{1}$ Por el carácter circunstancial de las acciones que enfrenta, la resistencia adquiere a veces rasgos de espontaneidad y desorganización sino es que de anarquismo. En general, la resistencia es asumida como un ejercicio social de contrapoder, como una acción sólo negativa, es decir, como una "reacción” más

1 Se habla así de acciones de resistencia por parte de despedidos de una empresa, de familiares de obreros que han sufrido accidentes mortales (mineros, trabajadores de la industria petrolera, etc.), de desplazados de territorios donde se planean construir emporios turísticos o comerciales, de comunidades indígenas que sufren discriminación o marginación, de mujeres víctimas de la violencia sexual, de homosexuales objeto de agresiones verbales o físicas, etc. 
que como una "acción", que no se propone objetivos claros como tomar el poder, cambiarlo, participar en él, esto es, actuar dentro del marco institucional-organizativo establecido, pues, de alguna manera, se asume que es todo ese marco el que está siendo cuestionando por la acción de resistencia. Normalmente los movimientos sociales de resistencia tienden a diluirse, aunque con el tiempo logran producir efectos y resultados positivos en el orden social existente (como el caso del EZLN en México).

Más que estudiar toda la complejidad que involucran los movimientos de resistencia social, nos proponemos en este ensayo analizar filosóficamente el concepto de "resistencia". Nos motiva también el dato interesante de que el término resistencia ha estado presente, a veces de manera sólo lateral, en reflexiones y elaboraciones de distintos filósofos de los últimos tiempos (particularmente nos ocuparemos de pensadores de la segunda mitad del siglo veinte y hasta nuestros días). Nuestra expectativa es que este análisis pueda servir para entender en una dimensión más profunda y consistente el sentido de los movimientos de resistencia a través del esclarecimiento del significado filosófico y ético-político del concepto de resistencia.

Expondremos a continuación nuestra tesis en los siguientes apartados: 1) El concepto fenomenológico y ontológico de resistencia (en Maurice Merleau-Ponty, Graham Harman y MaurizioFerraris); 2) El concepto político de resistencia, a través del magnífico análisis que hizo el filósofo francés Gilles Deleuze del pensamiento de su compatriota Michel Foucault, particularmente de su teoría del "poder y la resistencia", y 3) La idea de una práctica política de la resistencia democrática como acción positiva y creativa (a manera de conclusión). La tesis que buscamos traslucir en todo este desarrollo es que la resistencia es el ejercicio originario y positivo del poder popular (democracia sustantiva), del demos, y que su objetivo último no estriba en combatir al poder político-estatal sino en evitar la 
identificación total, y siempre mistificadora, entre el demos y el poder (el Estado), el sometimiento total, la absorción o disolución del primero en el segundo. La resistencia del pueblo al poder significa no sólo enfrentamiento a un poder externo y establecido, sino el evitar que el poder se enquiste en el propio pueblo y extermine así su potencia crítica y creadora, que es a la vez poder ético y ejercicio de la libertad. Al contrario de lo que normalmente se asume, aquí buscamos mostrar que la resistencia no es segunda respecto al poder, al Estado, sino primera, originaria, es decir -y es la hipótesis de este ensayo- ontológica. La resistencia es a la vez origen del Estado (éste es más bien acto de "contra-resistencia") y ámbito ontológicosocial irreductible al Estado y a cualquier forma de poder. Todavía más, "resistencia" es el carácter mismo de lo Real, del Ser, en cuanto potencia pura. El movimiento de lo ontológico a lo político implica también un regreso de lo político a lo ontológico, esto es, una concepción de lo "político" como ámbito de contingencia y creatividad, y, por ende, como la exposición o expresión por excelencia del Ser. ¿Qué entendemos entonces por resistencia?

\section{El concepto fenomenológico y ontológico de resistencia}

El término resistencia ha aparecido en ciertas posturas filosóficas que se proponen cuestionar el dominio de las posiciones idealistas, subjetivistas y humanistas propias del pensamiento moderno, para las cuales la razón humana es capaz de entender y dominar todo lo existente bajo el supuesto de la inteligibilidad total de la realidad. El supuesto último es la idea de "transparencia": nada escapa a la mirada humana, a la indagación del sujeto. Contra esta idea varios pensadores esgrimen la idea de "opacidad" y, por ende, de "resistencia". La realidad viene a ser definida ahora como lo que "resiste", lo que pone cotos al imperio de una razón cognoscente y ordenadora demasiado dueña de sí misma y a una concepción del ser y de lo 
real como mero correlato, perfecto y feliz, del pensamiento y las prácticas cognitivas. Abordamos en seguida varios planteamientos que asumen, por el contrario, el carácter de resistencia para definir y comprender lo real, el Ser. Lo real o lo que resiste, lo que se resiste. Por ende, se sigue de lo anterior, lo que no resiste es lo irreal, la irrealidad; la pura construcción mental es la no resistencia.

\section{El concepto fenomenológico de resistencia}

Emmanuel Alloa, estudioso, entre otros temas, de la filosofía de Merleau-Ponty, publicó un libro en el que destaca la tesis que aquí vamos adelantando, y que lleva por título: La résistance $d u$ sensible. Merleau-Ponty critique de la transparence (Alloa, 2008). Se trata claramente, y así lo observa Alloa, de un planteamiento que se contrapone al pensamiento más reconocidamente atribuido a Edmund Husserl, el fundador de la filosofía fenomenológica, quien centra la tarea de la reflexión en el esclarecimiento de la vida interior de la conciencia como condición para el esclarecimiento de la realidad exterior. Sin renunciar totalmente al procedimiento fenomenológico, Merleau-Ponty buscó alejarse de esa concepción y, al menos, darle igual importancia a la capacidad del pensamiento para abrirse a lo que no es pensamiento, a lo que no es conciencia, al mundo tal cual. En ninguna otra parte resulta evidente esta perspectiva como en el apartado dedicado a "La cosa o lo real" de su obra magna, Fenomenología de la percepción. El filósofo francés llega ahí a los límites de una descripción fenomenológica del mundo:

No lo advertimos, de ordinario, porque nuestra percepción, en el contexto de nuestras ocupaciones, se posa en las cosas nada más que lo suficiente para reencontrar su presencia familiar, pero no lo bastante para redescubrir lo que de inhumano se oculta en ellas. Ahora bien, la cosa nos ignora, reposa en sí. Lo veremos si ponemos en suspenso y dirigimos a ella una atención metafísica 
y desinteresada. Luego, es hostil y extraña, no es ya para nosotros un interlocutor, sino un otro decididamente silencioso, un Sí (soi) que se nos escapa tanto como la intimidad de una conciencia extraña (Merleau-Ponty, 1977: 336).

Este reposar en sí de la cosa, el ser-ahí como ignorando totalmente nuestra presencia, es lo que Alloa llama la "resistencia de lo sensible", es decir, el que lo Sensible (el mundo aprehendido por nuestros sentidos) se aparezca, tal como Merleau-Ponty mostró a lo largo de su obra, como algo que resiste a los poderes constituyentes de la Conciencia, a la manera de Husserl (particularmente el Husserl de las Ideas; Husserl, 2013). Pero, todavía más, que escapa también a los poderes constituyentes del cuerpo vivido y actuante -la conciencia encarnada que Merleau-Ponty convirtió en el sustrato de la experiencia fenomenológica-. Es decir, el filósofo francés nos muestra en la caracterización de la cosa como "ser de resistencia” los límites no sólo de la fenomenología de Husserl sino los de la suya propia, en fin, los límites de toda filosofía fenomenológica. Esa resistencia, y la propia resistencia de Merleau-Ponty a permanecer en el mundo áureo de la filosofía de la conciencia, lo llevará a dar el paso en su última obra desde la fenomenología hacia la ontología (Merleau-Ponty, 1970; Ramírez, 2013). Esto es, a la revelación del Ser como aquello que traspasa el ámbito de la "claridad y distinción" de la filosofía reflexiva, y hace de la opacidad, la distancia, el espesor, no caracteres meramente "negativos", definidos sólo en función de la manera como obstaculizan o no el "acceso" de la conciencia a lo que existe, sino como caracteres positivos del propio Ser, de lo real. Según Merleau-Ponty:

Lo real se distingue de nuestras ficciones porque, en él, el sentido inviste y penetra profundamente a la materia. (...) Lo real se presta a una exploración infinita, es inagotable. Por eso los objetos humanos, los utensilios, se nos manifiestan como pro-puestos en 
el mundo, mientras que las cosas están arraigadas en un fondo de naturaleza inhumana. La cosa es para nuestra existencia no tanto un polo de atracción como un polo de repulsión. Nos ignoramos en ella, y es esto lo que hace de la misma una cosa (Merleau-Ponty, 1977: 337-338).

No obstante su radicalismo fenomenológico, Merleau-Ponty sigue de alguna manera concibiendo a lo real como un correlato (aun "en negativo") del sujeto corporal humano. Lo que define lo real es la posibilidad de ser objeto de una "exploración infinita": esta definición supone que hay un "sujeto explorador" (lo que ya pensaba Kant, cuando define a la idea trascendental de "mundo" como el polo ideal de la acción indefinida de un sujeto cognoscente). 2 Más allá de la fenomenología, pensadores posteriores irán ahondando en la idea de lo real como trascendencia absoluta e infinita (o indefinida) respecto al Yo de la conciencia. Por ejemplo, bajo enfoques muy distintos, Emmanuel Levinas y Jean-Luc Nancy: la resistencia del "Otro" al Sí mismo en el primero, y la resistencia de la "existencia infinita" a la significación humana en el segundo (Levinas, 1977; Nancy, 2003). De alguna manera estos pensadores dieron lugar a la posibilidad de una perspectiva directamente ontológica (post-fenomenológica), de lo que nos ocupamos en el siguiente apartado.

\section{El concepto ontológico de resistencia}

En la corriente filosófica del "nuevo realismo" -o realismo especulativo- (Ramírez, 2016), surgida en años recientes y como reacción contra el posmodernismo, el concepto de resistencia ocupa un lugar importante en algunas de sus figuras representativas. Al

2 La totalidad no como realidad objetiva sino como idea regulativa del proceso del conocimiento (Cf. Kant, 2009: 492). 
proponerse recuperar la primacía de la ontología y, por ende, la primacía de lo Real sobre la Conciencia, el nuevo realismo ha insistido en el carácter irreductible de la realidad tanto a las nociones de la metafísica dogmática tradicional como a las determinaciones de la epistemología con las que la modernidad en general ha querido definir perentoriamente lo real. Para el pensamiento moderno, particularmente a partir de Kant, la realidad es el mundo de los fenómenos que puede ser capturado por un discurso o un saber científico. Más allá, nada sabemos o nada hay. La rebelión del nuevo realismo contra esta manera de pensar y a favor del reposicionamiento de lo real (de lo real tal cual es, de la cosa en sí) y de la capacidad del pensamiento para sustentarlo se expresa de diversas maneras, según los pensadores que asumen tal posición. Para Quentin Meillassoux, el iniciador del realismo especulativo, la "resistencia" de lo real está implicada en el principio ontológico, que él propone, de la contingencia radical de todo lo que existe (Meillassoux, 2015). En la medida en que el Ser es contingente, y necesariamente contingente (no hay otra opción),3 él puede ser más, mucho más, de lo que se nos "aparece" a nosotros, más de lo que nosotros (los humanos) podemos determinar según nuestros marcos epistémicos, metodológicos o lingüísticos. Para Meillassoux, la resistencia de la contingencia del Ser es claramente un rasgo del propio Ser y no se define únicamente en su relación (negativa o positiva) con el sujeto cognoscente. Por eso sólo puede ser afirmada a través de una razón especulativa, de una razón pura.

3 Meillassoux no sostiene, como Hegel, que necesidad y contingencia son lo mismo; no dice que un ente es a la vez contingente y necesario (lo que es una mera contradicción lógica); dice que la contingencia es lo único que existe, que el Ser es plenamente contingente y no puede no serlo, por ende, que la contingencia en cuanto tal es lo único necesario, y es así que ella puede ser afirmada de forma absoluta y verdadera. No hay razón (ontológica) de lo que existe (principio de irrazón o de hiperfacticidad), y reconocer esto es el acto máximo (ciertamente, vertiginoso) de nuestra razón. 
Estamos más allá del "correlacionismo" sujeto-objeto o mentemundo del pensamiento moderno.4

Es en la propuesta del filósofo norteamericano neo-realista Graham Harman donde mejor queda expuesto el concepto ontológico de resistencia (Harman, 2015). Él propone superar en definitiva la filosofía del sujeto que signa a todo el pensamiento moderno a través de una filosofía u ontología radicalmente orientada a los objetos. Una filosofía centrada en el objeto es la vía más segura para superar el subjetivismo posmoderno y restablecer claramente la prioridad de la ontología. Ahora bien, la originalidad de Harman estriba en que más que eliminar al sujeto su propuesta consiste en integrar al propio campo ontológico aquello que se le atribuía a él. De esta manera, sostiene la tesis de que el sujeto es un "objeto" más, que no posee ningún privilegio, y que las "cualidades subjetivas" (lo que supuestamente pone el sujeto en la relación de conocimiento) deben transfigurarse y ubicarse ontológicamente (en cualidades del objeto). Harman plantea sustituir la dicotomía sujeto-objeto del pensamiento epistemológico y fenomenológico moderno por la dualidad ontológica objeto sensual / objeto real; donde el primero caracteriza todo el ámbito relacional de los objetos, la manera como ellos se relacionan entre sí de distintas e infinitas maneras (la relaciones ontológicas no se reducen a la relación con el "sujeto"), y el segundo, el objeto real, define la extraña (pero necesaria) propiedad del objeto de retraerse sobre sí mismo, de retirarse a un fondo inaccesible pero real, es decir, de constituirse en una especie de "sustancia" aristotélica, unitaria y autónoma. Este retiro es lo que podemos concebir en términos de resistencia del objeto: el objeto real es lo que resiste y se resiste a ser absorbido no sólo por la conciencia humana sino por cualquier otro objeto.

4 El concepto de "correlacionismo" para caracterizar todo el espectro del pensamiento moderno y posmoderno es un aporte fundamental de la filosofía de Meillassoux (2015) 
Para mayor entendimiento, cabe referir aquí el concepto de la "tercera mesa" que Harman ha expuesto en un ensayo reciente. En la tradición de la filosofía moderna se ha hablado de dos mesas, la mesa que es objeto de la experiencia cotidiana (tema de la fenomenología) y la mesa que es objeto de la teoría física, es decir, como un conjunto de partículas atómicas que se ajustan ciertas regularidades objetivas. Ambas posturas se han contrapuesto siempre, cada una reivindicando para sí que su "mesa" es la real y que la otra es irreal: para la postura fenomenológica la mesa del físico es una mera construcción teórica, mientras que para la postura físicomaterialista la mesa del fenomenólogo es una especie de ficción o de fantasma (un "epifenómeno" de la conciencia). Esta contraposición ha atravesado el pensamiento del siglo XX y se ha mostrado, en general, como el conflicto irreductible entre las dos culturas: la humanista y la científica. Harman propone salir de este falso conflicto asumiendo que ambas mesas son irreales y que la mesa real es una sustancia que se retrae (resiste) a sus manifestaciones fenoménicas tanto como a su composición físico-corpuscular, y que permanece oculta e inaccesible frente a toda pretensión de agotamiento completo de su ser.

La tercera mesa se sitúa justo entre las otras dos, ninguna de las cuales es realmente una mesa. Esta tercera mesa emerge como algo distinto a sus componentes y también se oculta detrás de sus efectos externos. Nuestra mesa es un ser intermedio que no es localizable a partir de la física subatómica ni la psicología humana, sino que habita una zona permanente y autónoma donde los objetos son simplemente ellos mismos (Harman, 2016).

No obstante, Harman considera que la mesa real, en su retiro sobre sí misma, es capaz todavía de emitir ciertos llamados, ciertas alusiones, indirectas, expresivas, ocasionales. De ahí que, según el filósofo norteamericano, sea el arte el modo en que los seres huma- 
nos hemos podido mantener un contacto con la cosa real, con la realidad de las cosas. El arte es, en verdad, la base para la constitución de la tercera cultura que buscamos, una que pueda superar en definitiva el dualismo, finalmente sin sentido, de las dos culturas que el siglo XX ha buscado defender o, vanamente, de superar y unificar de forma parcial. Sólo el arte nos permite mantener la resistencia de lo real sin destruirla -pues esa resistencia es el sentido de lo real-y, a la vez, sin conformarnos con dejarla en un silencio absoluto, en un retiro puramente pasivo e improductivo.

El filósofo italiano Maurizio Ferraris, quien dio un giro desde la hermenéutica hacia el nuevo realismo, es la única figura de esta nueva corriente filosófica que ha usado explícitamente el término resistencia para definir su propia concepción. Ferraris caracteriza al objeto real, y a lo real en cuanto tal, como lo inenmendable, lo que resiste, esto es, lo que escapa a nuestras determinaciones intelectuales, a nuestras acciones intencionadas o nuestras planificaciones sistemáticas.

la inenmendabilidad se manifiesta esencialmente como un fenómeno de resistencia y de contraste. Yo puedo abrazar todas las teorías del conocimiento de este mundo, puedo ser atomista o berkeleyano, postmodernista o cognitivista, puedo pensar, con el realismo ingenuo, de que lo que se percibe es el mundo falso. Permanece, no obstante, que lo que percibimos es inenmendable, no es posible corregirlo: la luz del sol es enceguecedora, y el mango de la cafetera quema, si la hemos dejado al fuego. No hay ninguna interpretación que oponer a estos hechos; las únicas alternativas son los anteojos de sol y los guantes (Ferraris, 2013: 49).

No obstante, Ferraris no quiere permanecer en un mero "negativismo", y propone una versión más amplia del realismo (que llega a llamar "realismo trascendental"), el que incluye, coincidiendo con Harman, una dimensión positiva aunque indirecta o alusi- 
va. En una entrevista reciente, Ferraris expresa su concepción del asunto:

Objeto, para mí, es la unidad mínima que resiste (realismo negativo), pero en conjunto tenemos además las ofertas de affordances (realismo positivo). Por lo tanto, en lugar de una definición del objeto puedo proporcionar una lista interminable: Napoleón era un objeto (murió en Santa Elena y no en Manhattan: resistencia; Napoleón permite escribir novelas y poemas: Affordances); el destornillador es un objeto (no permite beber, resistencia; pero se puede atornillar o atacar a alguien: Affordances), etc. (Ralón y Ramírez, 2016).

El término affordance, proveniente de la psicología cognitiva y luego de la informática, significa, más o menos, ofrecimiento, disposición, es decir, las posibilidades de actuación que un objeto o una situación permite, más allá de sus determinaciones meramente objetivas o funcionales (de sus resistencias). Consiste en una relación entre el objeto y el agente, no es pues una propiedad del propio agente ni del objeto por separado. La affordance no elimina la resistencia del objeto pero tampoco nos deja en la inacción. Entre la mera pasividad y la pura acción se encuentra la "enacción": el aprendizaje a través de la práctica (aprender a andar en bicicleta conduciendo una, por ejemplo). Es acción vinculada a un objeto o un contexto: no sobre un objeto o contexto sino desde un objeto o contexto. La affordance o la enacción no elimina la resistencia sino que la aprovecha o la hace productiva; la transfigura en potencia expresiva. Retomaremos este concepto adelante, ya desde el punto de vista de una ontología política (o una política ontológica). 


\section{La resistencia política}

Como decíamos al inicio, el tema de la resistencia se encuentra inmediatamente vinculado a la dimensión política del movimiento social. Transitamos ahora del plano puramente ontológico al plano político. No es un cambio radical de tema, pues en realidad lo que nos interesa es el planteamiento de un concepto ontológico de lo político y de uno ontológico-político de la resistencia. Para esto, proponemos retroceder un poco; naturalmente, a la reconocida teoría de Michel Foucault. Como sabemos, el filósofo francés se ocupó de un modo inédito de los temas del poder, el Estado, la lucha social, etc. Ciertamente, Foucault tenía más talante de historiador, de investigador social, que de filósofo puro (de ahí quizá su éxito en las distintas disciplinas sociales). No obstante, su colega y amigo, el filósofo Gilles Deleuze, se permitió dedicar unos breves ensayos al esclarecimiento del significado más esencialmente filosófico de las tesis, las teorías y los desplazamientos teóricos presentes en el desarrollo de su pensamiento. Nos basamos en estos ensayos para dar cuenta del concepto político-ontológico de resistencia (que remite, de alguna manera, a la filosofía de la dupla Foucault/Deleuze).

Deleuze presenta una reconstrucción sistemática de la filosofía de Foucault en torno a dos ejes: uno de las problemáticas y otro de la cronología. Siguiendo el desarrollo del pensamiento foucaultiano, distingue tres problemáticas y tres etapas sucesivas, que muestran el proceso de construcción, en verdad de invención de tal pensamiento: la manera como cada categoría -saber, poder, pensar- es empujada por la anterior a surgir. Sólo en este proceso se puede entender en todo su sentido la originalidad de las nociones foucaultianas de Poder y Resistencia. Veamos:

1) La etapa epistemológica, que corresponde a las obras iniciales de Foucault, de fines de los 50 hasta El orden del discurso (el dis- 
curso de ingreso a El Collège de France de 1970; Foucault, 2013). La problemática que se plantea aquí es la de la consistencia del "saber", es decir, de la relación entre las palabras y las cosas (entre el discurso y la realidad, entre hablar y ver, entre el régimen de discursividad y el régimen de visibilidad, etcétera). Coincidente con la epistemología estructuralista, Foucault asume la tesis de una discontinuidad entre ambas instancias; cada orden posee su propio, y autónomo, régimen de operación, según reglas, materialidades y funcionamientos diversos. Foucault asume entonces que no solamente el "discurso" obedece a ciertas reglas y condiciones sociales y culturales que determinan lo que puede "decirse", sino que el propio campo de "experiencia" se encuentra estructurado también según ciertos órdenes y regularidades que determinan lo que puede "verse". Así, el problema de la verdad queda replanteado en los siguientes términos: ¿cómo y por qué se produce una "correspondencia” entre los dos regímenes? Contra el sentido común y contra las epistemologías positivistas, Foucault considera que esa correspondencia (o "adecuación") no es un proceso espontáneo o natural. No es algo dado o algo que pueda definirse solamente desde el puro orden del discurso o desde la mera experiencia. Un tercer elemento, más allá de las palabras y las cosas, está llamado a intervenir: el "poder". Es necesario así operar un primer desplazamiento: desde la epistemología hacia la teoría política.

2) La etapa política, que corresponde a la obra intermedia de Foucault 5 y que tiene por problemática central la naturaleza del poder. Como es sabido, el filósofo francés introduce en el pensamiento contemporáneo una inédita y original concepción del poder que básicamente consiste en observarlo en su dimensión operante y no sólo en sus niveles institucionales (el Estado, el orden jurídico, los partidos políticos, etcétera). Adicionalmente, otra tesis novedosa de Foucault consiste en la idea de la positividad del

5 Significativamente representada por Foucault (1976). 
poder, es decir, que él no actúa sólo negativamente, reprimiendo, dominando, suprimiendo, sino también, y quizá de modo más eficaz, a través de acciones positivas como ordenar, conducir, inducir, definir, etc. Desde este punto de vista, y en relación con la problemática referida en el anterior apartado, una función fundamental del poder consiste en producir saber, en producir "verdad". Es el poder quien impone la correspondencia o el ajuste entre los planos del decir y del ver, entre el discurso y la experiencia. La articulación entre las formas del saber y las formas del poder está a la base de las formaciones "manifiestas" de lo político: el Estado, el aparato jurídico, la legislatura, los procedimientos de elección, etc.

En un sentido más específico, las formas del poder son llamadas por Deleuze diagramas. ¿Qué es un diagrama? Es la formalización o codificación de una relación de fuerzas característica, es decir, el modo práctico-social en que el poder opera ante todo. Por ejemplo, la relación entre un sujeto dominante que otorga protección y un sujeto sometido que ofrece su labor (el seńor feudal y el siervo), o entre uno que enseńa asumiéndose como dueño del saber, y otro que recibe y asimila ese saber asumiéndose como carente de él (la relación profesor-alumno). Según Deleuze, un diagrama configura una relación de fuerzas (composición de fuerzas activas y fuerzas reactivas), y tiene, por ende, dos caras: una que apunta a las estructuras de poder que sustenta, y otra que apunta hacia el campo libre de fuerzas en que se apoya. Ahora bien, ese campo de fuerzas en cuanto tal rebasa al diagrama y a todo orden de saber-poder. Es el "Afuera" de toda determinación epistémica, social o política. Es una dimensión ontológica donde las fuerzas fluyen libremente, caóticamente incluso, constituyendo así, precisamente, el espacio originario de la resistencia. Es en este sentido, y Deleuze insiste en el punto, que "la resistencia es primera" respecto al Poder (Deleuze, 1987: 119). En contra de lo que se asume normalmente, la resistencia no aparece sólo después, frente a un Poder ya consti- 
tuido (un Estado), como acción de enfrentamiento o como lucha revolucionaria (que busca cambiar al Poder). La resistencia está en el fondo del poder: es su base primigenia, de donde proviene, pero es a la vez aquello que se le escapa y que él busca atrapar, vencer. Por su naturaleza misma, la resistencia traspasa, rebasa al poder por todas partes. La dualidad poder-resistencia es, pues, constitutiva de todo el campo social.

De esta manera, podemos redefinir el significado político de la resistencia. Aquello a lo que se resiste es al Poder, es decir, a la disolución de la separación entre lo que está fuera del Poder y el propio Poder (el Estado) o, de otra manera, "resistir" es evitar que el Poder domine todo, controle todo. Es resistir a que el poder se enquiste, se enseńoree en el propio campo social, es resistir a volverse parte de él. Se trata de mantener la libertad pura y la indeterminación constitutiva, la informalidad e incodificabilidad del campo social; la potencia de lo que es contra el poder y la dominación de lo dado. Esto es la resistencia. Eso es resistir.

El antropólogo Pierre Clastres puso las bases para el entendimiento preciso de esta perspectiva cuando sostuvo que las llamadas sociedades primitivas no son en realidad sociedades sin Estado (y que estarían avanzando teleológica y necesariamente hacia él) sino, en verdad, sociedades contra el Estado (Clastres, 1974). Clastres hace estudios etnográficos de los Yanomami del Brasil y otros grupos indígenas de Sudamérica. La organización y la actividad colectiva de estas sociedades está hecha (mediante su conformación en sociedades guerreras permanentes) para evitar que el Estado advenga en ellas, para evitar que un Poder sustantivo y enajenado del cuerpo social se constituya en ellas. Mediante un devenir permanente, las sociedades contra el Estado logran mantener la resistencia originaria que da sentido, verdad, intensidad y libertad pura a sus vidas y sus acciones. Ahí, como dice Deleuze, "la resistencia deviene poder de la vida, poder vital que no se deja detener". 
3) La etapa ética, que corresponde a la última obra de Foucault, y plantea la problemática de si existe una dimensión adicional, una opción más allá del Poder, es decir, una capacidad de la resistencia para convertirse en algo propio y positivo. Viene aquí el segundo desplazamiento de problemáticas: de la teoría política a la reflexión ética. Deleuze observa un último giro en el pensamiento de Foucault a partir de sus estudios sobre la historia de la sexualidad en la antigüedad clásica (Grecia y Roma; Foucault, 1986-1987). Lo que estos estudios le permitieron fue encontrar otra posibilidad del campo de fuerzas, del Afuera: su redoblamiento en un Adentro, una dimensión reflexiva más profunda que toda subjetividad, que toda interioridad. Deleuze usa la figura del "pliegue" para caracterizar ese redoblamiento. Hay un punto singular donde las fuerzas se "pliegan", se flexionan y reflexionan, y da lugar a la posibilidad de una subjetividad (el sujeto como "efecto", ya no como causa o principio). De esta manera, más allá del saber y el poder, Foucault nos abriría a una tercera y original función: el Pensar, también bajo una redefinición de su sentido. Pensar, para Deleuze y Foucault, es la única actividad que permite captar lo no-estratificado, lo informal, el Afuera, el campo de fuerzas, la resistencia, es decir, lo "indeterminado", las singularidades infinitas, el apeiron (el hípercaos de Meillassoux). Pensar, es decir, la filosofía (el filosofar) es, así, componente fundamental del campo de resistencia. Pensar es resistir (resistirse), "es experimentar, es problematizar" (Deleuze, 1987: 151).

\section{Democracia trascendental}

Una forma de aterrizar los anteriores planteamientos es en torno a una redefinición filosófica del concepto de democracia y de práctica democrática. Precisamente se trataría de definir a la democracia como el campo ontológico-político de la resistencia, como el ám- 
bito de lo social irreductible a ningún estrato, a ninguna forma, a ninguna organicidad. En todo caso, cabe hablar de la democracia en dos sentidos: como el campo social desestratificado, el flujo libre de afectos y acciones, y como un régimen político, como un orden de procedimientos y regularidades institucionales.

Así pues, la vida democrática no se reduce al régimen democrático. La voluntad democrática también se expresa en la abstención, el voto nulo, la manifestación pública, la denuncia y la protesta social, la libertad de expresión, la resistencia civil, la crítica del poder y el llamado a cuentas. No sólo en las elecciones, no sólo en los órdenes políticos estatuidos. Democrático es un régimen donde el Poder nunca absorbe al Pueblo; donde el "pueblo" permanece, en su libre indeterminabilidad y en su irreductibilidad insustancial, como la instancia crítica de todo poder establecido, como resistencia permanente. Es decir, como el inalienable poder instituyente que ningún poder instituido puede presumir agotar o buscar sustituir o suplantar. Esta potencia abierta y al fin "ingobernable", esta "anarquía coronada", como la llama Deleuze, constituye la soberanía popular en cuanto verdad última e insumisa de la democracia. El genio ilimitado e ilimitable del demos significa que el pueblo nunca puede ser determinado en una única acepción, en un único sector, en una única representación; es lo abierto, plural e indeterminado por excelencia. Lo irrepresentable. Éste es el principio 'trascendental' de la democracia -que opera en lo real como el principio "crítico" de la política-: el pueblo existe ante todo en estado 'virtual' o 'ideal', como una multiplicidad pura que siempre se está realizando y nunca se realiza de forma última. Nadie puede hablar en su 'nombre', pero todas las voces dan cuenta de su realidad inagotable, de su potencia irreductible (Cf. Lefort, 1990: 187-195; Ramírez, 2011: 105-120). Esto es la democracia real, sustantiva. La democracia como ejercicio crítico de la resistencia. 
Podemos decir entonces que la vida democrática resiste al Estado, incluso, y ante todo, al Estado democrático. Hemos visto, desde la segunda mitad del siglo XX, cómo el poder es capaz de usar los procedimientos formales de la democracia para afianzarse y ensanchar su dominio. Por esto, la esperanza emancipadora no se puede poner en algún tipo de Estado, debemos mantener la irreductibilidad del pueblo, su "ingobernabilidad", como principio de la democracia. Como dice Jacques Rancière:

Las tan corrientes quejas sobre la ingobernabilidad de la democracia remiten, en última instancia, a esto: la democracia no es ni una sociedad por gobernar ni un gobierno de la sociedad. Es, propiamente esa ingobernabilidad sobre la cual todo gobierno debe, en definitiva, descubrirse fundado (Rancière, 2007: 74).

El gobierno democrático no es, pues, imposible. Al contrario, es un gobierno fundado, aunque fundado en el reconocimiento de la ausencia de fundamento, o como venimos diciendo aquí, en el reconocimiento del pueblo (el demos) como resistencia originaria, permanente e insuperable; como la "cosa en si" de lo social que se retira a toda determinación, como la contingencia radical del existir en común (Nancy, 2001), como la pluralidad irreductible de lo común que imposibilita a la vez que lo común pueda ser nombrado, representado o apropiado (Laval \& Dardot, 2015). En esto consiste la verdadera sabiduría política, "el principio mismo de la política, el principio que instaura a la política fundando el 'buen' gobierno en su propia ausencia de fundamento" (Rancière, 2007: 59).

Pero la resistencia como cualidad originaria de la democracia sólo aparece como límite negativo respecto al poder que busca capturarla y deshacerla. En sí misma, y ésta sería la enseñanza del realismo especulativo, esa resistencia tiene la posibilidad de lo que Ferraris llama la "affordance", y que aquí vamos a entender como 
toda la actividad libre y creadora (enacción) de que es capaz el cuerpo social, y que se expresa relevantemente en lo que tradicionalmente se ha concebido como el mundo de la cultura: el arte, la ciencia, la vida ética, el pensamiento filosófico. Ciertamente, en cada uno de estos ámbitos puede reproducirse la dualidad resistencia/poder, la actividad cultural puede ser apropiada por los mecanismos del poder y convertirse en mero mecanismo ideológico de justificación o de evasión. No obstante, y he ahí la importancia del pensar y de la filosofía, existe siempre la posibilidad de remitir las obras culturales (los "productos" culturales) al ámbito inalienable de su génesis, a su incontrolable e incontorneable proceso de producción: el campo "trascendental" de la resistencia, cuya cualidad última es, precisamente, ontológica: el Ser mismo de todo lo que existe, de todo lo que resiste.

\section{Bibliografía}

Alloa, Emmanuel, 2009, La resistencia de lo sensible. Merleau-Ponty crítico de la transparencia, Buenos Aires, Nueva visión.

Clastres, Pierre, 1974, La societé contre l'État. Recherches d'antropologie politique, Paris, Minuit.

Deleuze, Gilles, 1987, Foucault, México, Paidós.

Ferraris, Maurizio, 2013, Manifiesto del nuevo realismo, Madrid, Biblioteca Nueva.

Foucault, Michel, 1976, Vigilar y castigar. Nacimiento de la prisión, México, Siglo XXI. XXI. ,2013, El orden del discurso, México, Tusquets. 
Harman Graham, 2016, "Thethirdtable", Laureano Ralón (trad.), disponible en: http://files.meetup.com/328570/Harman\%20 -\%20The\%20Third\%20Table.pdf (consultado: 10/V/2016)

,2015, Hacia el realismo especulativo. Ensayos y conferencias, Buenos Aires, Caja Negra.

Husserl, Edmund, 2013, Ideas relativas para una fenomenología pura y una filosofía fenomenológica. Libro primero: introducción general a la fenomenología pura, México, FCE/UNAM.

Kant, Emmanuel, 2009, Crítica de la razón pura, México, FCE/ UNAM/UAM.

Laval, Christian y Pierre Dardot, 2015, Común. Ensayo sobre la revolución en el siglo XXI, Barcelona, Gedisa.

Lefort, Claude, 1990, "Democracia y advenimiento de un lugar vacío", en Id., La invención democrática, Buenos Aires, Nueva visión.

Levinas, Emmanuel, 1977, Totalidad e infinito, Salamanca, Sígueme.

Meillassoux, Quentin, 2015, Después de la finitud. Ensayo sobre la necesidad de la contingencia, Buenos Aires, Caja negra.

Merleau-Ponty, Maurice, 1970, Lo visible y lo invisible, Barcelona, Seix-Barral. , 1977, Fenomenología de la percepción, Barcelona, Península.

Nancy, Jean Luc, 2003, El olvido de la filosofía, Madrid, Arena. , 2001, La comunidad desobrada, Madrid, Arena.

Ralón, Laureano \& Ramírez, Mario Teodoro, 2016, “Interview with Maurizio Ferraris", Figure/Ground, 12 de mayo, disponible en: http://figureground.org/interview-with-maurizio-ferraris/ (consultado: 10/V/2016). 
Ramírez, Mario Teodoro, 2011, "Singularidad, comunidad e igualitarismo radical", en Humanismo para una nueva época. Nuevos ensayos sobre el pensamiento de Luis Villoro, México, Siglo XXI. , 2013, La filosofía del quiasmo. Introducción al pensamiento de Merleau-Ponty, México, FCE.

, (coord.), 2016, El nuevo realismo. La filosofía del siglo XXI, México, Siglo XXI. Incluye textos de Meillassoux, Markus Gabriel, Graham Harman y Maurizio Ferraris, además de estudios sobre sus filosofías.

Rancière, Jacques, 2007, El odio a la democracia, Buenos Aires, Amorrortu.

Recibido: 11 de mayo de 2016 Aceptado: 15 de agosto de 2016 